\title{
O design para a transformação social: uma análise dos coletivos urbanos de Belo Horizonte (MG)
}

Design for social change: an analysis of the urban collectives of Belo Horizonte (MG)

BATISTA, Mylene F.; Mestranda em Design; Universidade do Estado de Minas Gerais

mylenefer.batista@gmail.com

RIBEIRO, RITA A. C.; Doutora em Geografia; Universidade do Estado de Minas Gerais rribeiroed@gmail.com

\section{Resumo}

O espaço público é o lugar de ação e intervenção dos coletivos urbanos, que visam promover o exercício da cidadania e a transformação da vivência urbana. Em Belo Horizonte, Minas Gerais, três coletivos se destacam pela atuação e impacto social: Micrópolis, Grupo Poro e o Movimento Nossa BH. É importante observar como a cidade aderiu ao processo de incorporação dos coletivos urbanos na cidade, visto que, comumente, a transformação do espaço público desenvolve a gentrificação. Diante disso, o trabalho apresenta o papel do design no desenvolvimento de ações nas quais os indivíduos se identificam e criam vínculos emocionais. Através da linguagem expressa pela metodologia de projeto, o designer pode evidenciar mensagens que repassem os valores locais e explorar potencialidades percebidas no espaço público. Mas, essa competência também se apresenta como desafio no exercício de sua atividade como meio de comunicação e mediador nas relações entre a cidade e as pessoas.

Palavras Chave: design social; coletivos urbanos; espaço público.

\begin{abstract}
Public space is the place of action and intervention of urban collectives, which aim to promote the exercise of citizenship and the transformation of urban living. In Belo Horizonte, Minas Gerais, three groups stand out for performance and social impact: Micrópolis, Grupo Poro and Movimento Nossa $\mathrm{BH}$. It's important to observe how the city adhered to the process of incorporation of the urban collectives in the city, since, commonly, the transformation of the public space develops gentrification. Given this, the work presents the role of design for development of actions in which individuals identify and create emotional bonds. Through the language expressed by design methodology, the designer can highlight messages that pass the local values and explore potentialities perceived in the public space. But this competence also presents itself as challenge in the exercise of its activity as means of communication and mediator in the relations between city and people.
\end{abstract}

Keywords: social design; urban collectives; public space. 


\section{Introdução}

Para um estudioso do espaço urbano é fundamental a compreensão de que a participação cidadã, o papel das instituições e a paisagem urbana compõem um sistema e uma relação de interdependência, ou seja, estão interligados, constituindo o funcionamento de uma cidade. Isso significa dizer que analisar o contexto de uma cidade através de seus sujeitos e conexões, além das teorias do planejamento urbano (que nem sempre demonstram uma visão ampla do estudo), permite encontrar uma pluralidade de significações. De acordo com Canevacci (2004), a leitura do espaço urbano está na interpretação de seus códigos sociais a partir de técnicas e métodos diversos que se comunicam e resultam numa linguagem urbana. Se a cidade é o palco do exercício da cidadania, a forma como ela é planejada e construída impacta a vivência de seus indivíduos.

Diante da complexa sociedade atual, torna-se um desafio estabelecer o equilíbrio desse sistema, através de uma dinâmica sociocultural e econômica que visa a conservação da diversidade e o exercício da sustentabilidade social na cidade. Cardoso (2008) considera o momento favorável ao pluralismo. A sociedade contemporânea vive em constante divergência, porém, ela se abre a novos saberes, novas posturas para a complexidade.

Assim, diferentes movimentos sociais e coletivos urbanos surgiram no final do século XX, se intensificando nos últimos anos com a proposta de pensar a vivência da cidade num contexto mais próximo da realidade das pessoas. Conforme Machado (2007), a literatura clássica considera os termos "comportamento coletivo" e "ação social" como a referência de investigação. Manifestamse a partir da condição de tensão, tendo "como objetivo, a partir de processos frequentemente nãoinstitucionais de pressão, mudar a ordem social existente, ou parte dela, e influenciar os resultados de processos sociais e políticos que envolvem valores ou comportamentos sociais" (MACHADO, 2007, p. 252). O autor também define a importância que atributos como interação, intenção, conexão, identidade e ação, expressam para a mudança social, enquanto papel fundamental na criação de um ambiente propício para os atores sociais.

Os coletivos urbanos, em geral, não possuem uma estrutura hierárquica e através do voluntariado buscam trabalhar intervenções na cidade em conjunto com a população. E quando a população se identifica, a abertura para uma participação cidadã e empoderamento social torna-se mais concreta. $\mathrm{O}$ empoderamento é justamente a ação contrária a rotina, é o questionamento.

Nesse cenário, o design possui competências para o desenvolvimento de ações nas quais os indivíduos confiam, se identificam e criam vínculos emocionais. $O$ designer ao incluir no projeto de intervenção urbana os valores culturais inerentes à população onde essa será realizada, corrobora para que os indivíduos que circulam na cidade, possam se identificar com esse objeto e possam se apropriar dele. Através da linguagem elaborada por uma metodologia de projeto, o designer pode evidenciar mensagens que repassem os valores locais e explorar potencialidades percebidas nesse espaço público.

Diante do exposto, o objetivo deste trabalho foi compreender a participação do design nas ações que visam a transformação do espaço público. Para tanto, o recorte da pesquisa está na análise dos coletivos urbanos de Belo Horizonte e suas intervenções para a criação de soluções que visem o melhor aproveitamento da cidade pelos cidadãos. Três coletivos urbanos são relevantes: Micrópolis, Grupo Poro e o Movimento Nossa BH. Para a seleção foram considerados o tempo de atuação na cidade, o impacto das intervenções, método de aplicação e como se comunicam com a população. 
Primeiramente, o trabalho contextualiza a cidade de Belo Horizonte nas transformações urbanas vigentes, para depois apresentar uma análise dos coletivos urbanos selecionados, conectando-os ao papel do design no processo, bem como seus desafios.

O design se qualifica para o desenvolvimento de soluções para questões de alta complexidade, com uma visão ampla e integrada do projeto, apoiada pela ação conjunta a outras disciplinas. "É neste contexto que a riqueza interpretativa e a habilidade visionária, características próprias desta disciplina, podem contribuir para o desenvolvimento de uma pluralidade de soluções e de cenários de futuro" (KRUCKEN, 2008, p. 23). Além disso, o design pode contribuir para o estudo da democracia e ser uma ferramenta para o exercício da cidadania, desde que sua contribuição seja fundamentada e embasada, o que justifica a importância de potencializar os estudos que relacionem design e espaço urbano.

\section{A transformação urbana na cidade de Belo Horizonte}

No Brasil, a intensa demanda por projetos de requalificação urbana teve início no final dos anos 1980 e início dos anos 1990 a partir do aumento dos movimentos sociais e dos coletivos urbanos (BATISTA, 2017; JAYME; TREVISAN, 2012). Esses projetos são elaborados pela parceria do poder público com a iniciativa privada e são desenvolvidos em cidades com caráter turístico, em sua maioria. No geral, eles possuem um caráter higienista e de gentrificação, pelo fato de produzirem novos hábitos e comportamentos, modificarem a dinâmica sociocultural e econômica do local e suscitar novos consumos.

Nas últimas décadas, essa requalificação vem sendo justificada pela valorização da cultura e das experiências locais. Mas, percebe-se a apropriação do patrimônio histórico, das tradições locais e da cultura popular como mercadoria e suporte, a fim de valorizar o debate da importância da revitalização, num discurso globalizado sobre o futuro das cidades (BOTELHO, 2006; JAYME; TREVISAN, 2012). Este discurso transformou a prática de conservar a cidade, que passou a ter mais valor local através da ressignificação urbana.

Esses projetos partem de uma concepção de mercado que implica uma gestão mista entre Estado e iniciativa privada na forma de intervir no patrimônio como mercadoria cultural, cuja lógica altera o sentido do lugar ao tomar o cidadão como consumidor, identificado pelo seu poder aquisitivo. Essa prática é, obviamente, segregatória (JAYME; TREVISAN, 2012, p. 368).

Os autores indicam que em Belo Horizonte os processos de intervenção dos espaços públicos parecem não seguir a direção da gentrificação, mesmo que se perceba a busca de embelezamento e mesmo higienização em alguns casos. O foco está na valorização do Centro e no desenvolvimento econômico, sem inserir a cidade no fluxo do turismo e consumo (MOREIRA, 2008).

[...] agora que muitas das intervenções já estão concluídas, é possível perceber que esse processo alterou a paisagem urbana do centro histórico da cidade sem, contudo, provocar grandes transformações no modo de vida de seus usuários. Talvez esses processos não tenham sido pensados unicamente como intervenções voltadas para o mercado, o entretenimento e o consumo cultural (JAYME; TREVISAN, 2012, p. 368).

Para Moreira (2008), as políticas de revitalização em Belo Horizonte buscam focar no público interno, não convergindo para a transformação do sentido e identidade local como demanda a cultura globalizada. A formatação dos projetos foca na solução de questões locais, estabelecendo uma conexão com o público afetado. Talvez, por este fato, as intervenções urbanas, elaboradas pelos coletivos urbanos, obterem maior receptividade da população. Elas buscam entender a forma 
como o cidadão se apropria do local que frequenta, e qual seu papel nessa apropriação.

No entanto, mesmo que a requalificação urbana não acarrete em novas relações sociais e de consumo, preservando os usuários locais que usufruem da cidade cotidianamente, é possível perceber a possibilidade de os espaços planejados e reconfigurados apresentarem usos não programados, bem como a transformação destes espaços em vários lugares, demarcando a sociabilidade e apontando novas interpretações.

\begin{abstract}
O Baixo Centro de Belo Horizonte, cenário de intervenções físicas recentes ancoradas no passado, experimenta, nos últimos anos, uma apropriação diferente e renovada, compartilhada com os usos tradicionais da região. Se a origem dessa movimentação pode não ser identificada com facilidade, a intensa utilização e apropriação dos espaços dessa área - que não estavam previstas na intervenção original - ligada, principalmente, a manifestações culturais diversas, permitem colocar em questão as discussões que apontam para o declínio do espaço público (JAYME; TREVISAN, 2012, p. 370).
\end{abstract}

O fluxo constante de pessoas na área, tanto diurno, pela circulação de pedestres e de veículos, quanto noturno, que em sua maioria, está relacionado às atividades culturais, indica que a população vem usufruindo de forma intensa dessa região. Assim, a região central de Belo Horizonte vem apresentando condições para a existência de uma multiplicidade de usos e públicos. Se alguns estudos apontam para modificações da convivência nos espaços públicos, como delimitações elitizadas e segregações, bem como o empobrecimento de sua vitalidade, há espaços urbanos que ainda mantêm a conservação da diversidade de pessoas, de atividades, de usos e culturas.

É fundamental que as investigações a respeito do espaço urbano busquem compreender o papel das intervenções nesses processos de ressignificação, qual a influência nas formas de apropriação do lugar por parte da população e que interpretações são feitas a partir das ações implantadas. Este questionamento norteia o entendimento em rede e amplia a visão do estudo, abrangendo as relações entre o espaço, a ação e o público, como veremos na atuação dos coletivos na cidade.

\title{
3 Design, práticas urbanas e os coletivos
}

Os coletivos urbanos, no Brasil, iniciaram suas atividades a partir do final do século XX, entre as décadas de 1980 e 1990, num contexto sociocultural de preocupação com as ações empreendidas pelo poder público, intensificando suas atividades nos últimos anos através de práticas culturais e urbanas voltadas para o exercício da cidadania e a transformação da vivência na cidade. Eles se caracterizam pelo trabalho voluntário e em rede, geralmente com parceria de instituições públicas e privadas e pela equipe diversificada - os integrantes costumam possuir expertises variadas, o que facilita a estrutura organizacional do coletivo, não havendo, porém, hierarquias. Em Belo Horizonte, três coletivos se destacam pela atuação e impacto social: Micrópolis, Grupo Poro e o Movimento Nossa BH. Esta análise procurou identificar as conexões com o design, a partir das ênfases e métodos aplicados pelos coletivos. Além de apresentar as contribuições do design para a atividade dos grupos, também foi identificado os desafios do design para se trabalhar o contexto urbano em conjunto às outras disciplinas.

\subsection{Mapeamento de cenários: Coletivo Micrópolis}

O Coletivo Micrópolis é um grupo independente constituído por arquitetos e urbanistas formados pela Universidade Federal de Minas Gerais (UFMG) e trabalha, desde 2010, com 
propostas que visam a transformação do espaço urbano e a vivência na cidade. Suas ações estão relacionadas com os questionamentos cotidianos que se reproduzem no espaço urbano, dentro do campo da arquitetura e urbanismo, pedagogia, ação cultural e design. Priorizam atuações em pequena escala, trabalhando sempre as particularidades e identidades locais que apontem novas possibilidades de engajamento da comunidade e a transformação do espaço.

Ações pontuais, a nível local, podem ter um efeito multiplicador e transformador na cidade, sem necessariamente se concretizarem como objeto construído. Partindo dessa premissa e da compreensão do contexto e do entorno imediatos, o grupo pretende realizar ações, projetos e discussões que transponham as fronteiras disciplinares da arquitetura e que estejam relacionados ao nível da microescala e do cotidiano (MICRÓPOLIS, [s.d.]).

Desde seu nascimento em 2010 até sua expansão para os dias atuais, o Coletivo Micrópolis realizou notórias intervenções como o jornal de bairro para a comunidade Calafate em Belo Horizonte; o espaço compartilhado Canteiro dos Pequis em Sete Lagoas, Minas Gerais; e a cartilha "Por que a rua dá medo?", dentre outras ações (Figura 1).

Figura 1 - Projeto Calafate, Canteiro dos Pequis e Cartilha sobre segurança nas ruas, respectivamente

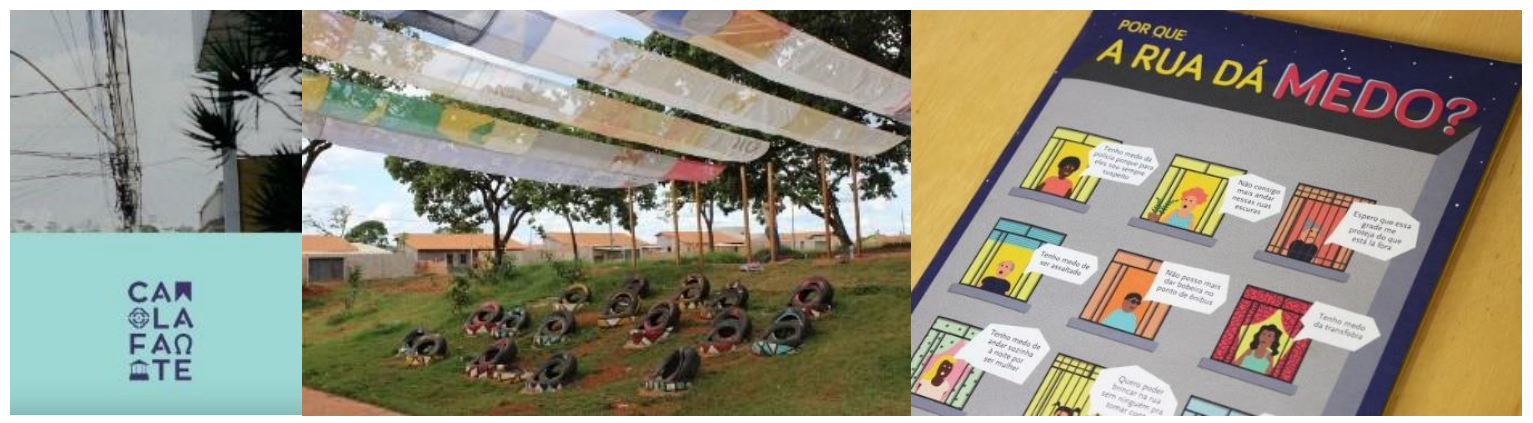

Fonte: micropolis.com.br (2018)

É interessante compreender o método utilizado no processo de desenvolvimento do jornal de bairro para a comunidade Calafate em Belo Horizonte. O Coletivo se instalou na região em 2014, e através da coleta de dados, imersão e experimentos em conjunto com a população local elaborou um processo de resgate do sentido do espaço público e do uso coletivo que culminou em mapeamentos processuais e na experimentação de um sistema de projetos com foco no resgate e na ressignificação do espaço público e no sentido de coletividade. Para tanto, a visão sistêmica no estudo do bairro possibilitou à equipe entender as reais necessidades da comunidade, o resgate dos costumes e das práticas urbanas e coletivas - ações que aconteciam na rua.

Apesar da efervescência da Rua Platina, do uso constante da praça Carlos Marques, das apropriações domésticas e dos encontros nas portas dos bares, é evidente no Calafate o gradativo encerramento na esfera privada das práticas que um dia se davam na rua. Isso é resultado, entre outras razões, do crescimento da sensação de insegurança na cidade e de processos urbanos impositivos que, ao longo dos anos e em nome da ordem e do progresso, foram inibindo manifestações festivas que povoavam as calçadas, praças e campos do bairro. Seja por falta de informação, medo, ausência de diálogo ou descrença na capacidade transformadora do cidadão comum, identificamos nos moradores e frequentadores do bairro um ceticismo na noção de espaço público, o que acaba por comprometer a noção de vizinhança (MICRÓPOLIS, [s.d.]).

Os espaços públicos urbanos se configuram como o cenário para o desempenho da vida 
pública. Refletem o trabalho e o lazer, a produção e o consumo, mas também são palco das inseguranças e medos. A intensificação do convívio em espaços públicos incita a interação entre as pessoas e a conexão com os lugares. Mas, isso contrasta com a cultura do medo que se manifesta na cidade; a sensação de perigo e a necessidade de proteção são manifestações comuns da insegurança moderna, como aponta Bauman (2009). O autor discursa que para um espaço público prosperar, ele deve promover a diversidade de pessoas, de atividades, de culturas.

Como resposta a esse contexto, propusemos um sistema constituído por projetos a serem desenvolvidos no bairro que testam o deslocamento da noção de espaço público para lugares outros, de modo a questionar seu significado desgastado e experimentar o reenvolvimento das pessoas em processos de ações coletivas que extrapolam os muros da esfera privada em direção às ruas do bairro (MICRÓPOLIS, [s.d.]).

As etapas de desenvolvimento do projeto (Quadro 1) não aconteceram de forma cronológica, mas simultaneamente.

Quadro 1 - Etapas de investigação no bairro Calafate

\begin{tabular}{ll}
\hline Etapa & Descrição \\
\hline Perceber o invisível & $\begin{array}{l}\text { Através de observações e diálogos com a comunidade, o grupo } \\
\text { documentou em mapeamentos as nuances e práticas socioespaciais } \\
\text { invisíveis do bairro, bem como aquilo que é perceptível à vista em } \\
\text { diferentes escalas - das calçadas do bairro a bases cartográficas já } \\
\text { existentes. }\end{array}$ \\
\hline
\end{tabular}

Investigar pela ação

Participando de eventos locais já existentes, o grupo elaborou processos híbridos de mapeamento e ação que catalisam o uso de determinados espaços, instigam a percepção dos envolvidos com o bairro e, ao mesmo tempo, informam sobre as relações de afeto e visões subjetivas sobre o território.

Preencher as lacunas

A partir de questionamentos formulados pelos mapeamentos e ações realizadas anteriormente, o terceiro momento explorou a experimentação de um sistema de projetos que visavam a reconquista, ressignificação e deslocamentos da noção atual de espaço público no bairro.

Fonte: adaptado de Micrópolis Bairro Calafate (2018)

Ainda que a metodologia do projeto não formalizou o uso do design no processo, tanto em ações táticas quanto em ações estratégicas, reconhece-se sua importância para direcionar as etapas processuais. Ao substituir questionários e métodos clássicos de abordagem por diálogos e convívio com a comunidade estudada, verificou-se um melhor engajamento do público nessas etapas. A visualidade e os elementos gráficos também foram um recurso bastante explorado, e através destes o usuário se tornou agente ativo no processo (Figura 2). 
Figura 2 - Ações na Praça Carlos Marques, bairro Calafate

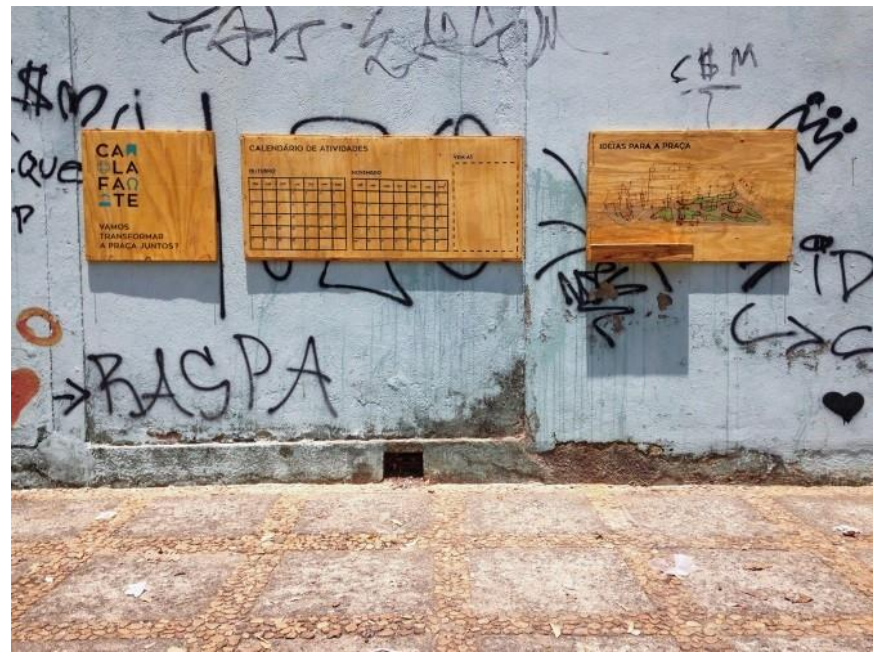

Fonte: micropolis.com.br/Praca (2014)

A partir da análise da ação do coletivo identificou-se que o mapeamento de cenários é uma estratégia condizente na elaboração de propostas que visam a transformação social de um lugar, apoiado pela visão ampliada do contexto, nas quais as informações são interligadas e pelo diagnóstico ser feito em campo, com a equipe inserida no cotidiano da comunidade. As referências coletadas foram estímulos para a associação de ideias. Os cenários, portanto, configuram exercícios de traçar futuros possíveis, a partir das possibilidades que o contexto oferece, que se traduzem em imagens ou mapas.

Em face disso, o design estratégico é um método apropriado para o objeto de estudo e apresenta um potencial de mediador nas relações sociais vigentes no lugar, acarretando um processo de compreensão e estruturação de um modelo síntese da realidade apresentada. É o momento que o designer e a equipe exploram os limites projetuais e apontam caminhos para a solução projetual.

\subsection{Experiência no espaço público: Coletivo Poro}

O contexto urbano atual, diante da sociedade em que vivemos, é dinâmico. Privilegia o consumo, a industrialização, o individualismo e a indiferença, enquanto a valorização dos espaços e das relações interpessoais é, muitas vezes, deixada de lado. Viver a cidade, criar vínculos e experiências, promover a comunicação, são formas de aproximar o transeunte do espaço urbano e melhorar o relacionamento entre a cidade e o público.

Os conceitos de bem-estar, desaceleração do ritmo, revalorização do tempo, contato e intercâmbio cultural, são fundamentais para a criação de novas relações e novas abordagens. 0 espaço urbano é o cenário da vida urbana das pessoas que por ele transitam, assim, o bem-estar poderá ser melhorado se forem desenvolvidas novas ações e interações através da experiência.

Estes apontamentos convergem em diferentes ações promovidas na cidade a fim de ressignificá-la, opondo-se ao empobrecimento das diversidades, que impacta a vitalidade da cidade e a experiência dos usuários. A importância de viver a cidade despertou o interesse de Brígida Campbell e Marcelo Terça-Nada, fundadores do Coletivo Poro. 
O Coletivo Poro realiza intervenções urbanas e ações efêmeras que questionam o cotidiano nos grandes centros urbanos. Se expressam através do design e da arte de forma a lançar questionamentos e discussões sobre os problemas da cidade e induzir o cidadão a participar do processo de intervenção. Para Bentz (2014), a construção de significado na produção artística e estética ocorre pela troca entre as pessoas, na veiculação de mensagens e percepções.

Como exemplo, Por Outras Práticas e Espacialidades foi uma ação realizada em 2010 pelo coletivo, através de cartazes afixados em locais públicos com mensagens que incitavam a reflexão. Estes cartazes foram disponibilizados no site do coletivo para livre acesso e compartilhamento (Figura 3).

Figura 3 - Cartazes do projeto Por Outras Práticas e Espacialidades

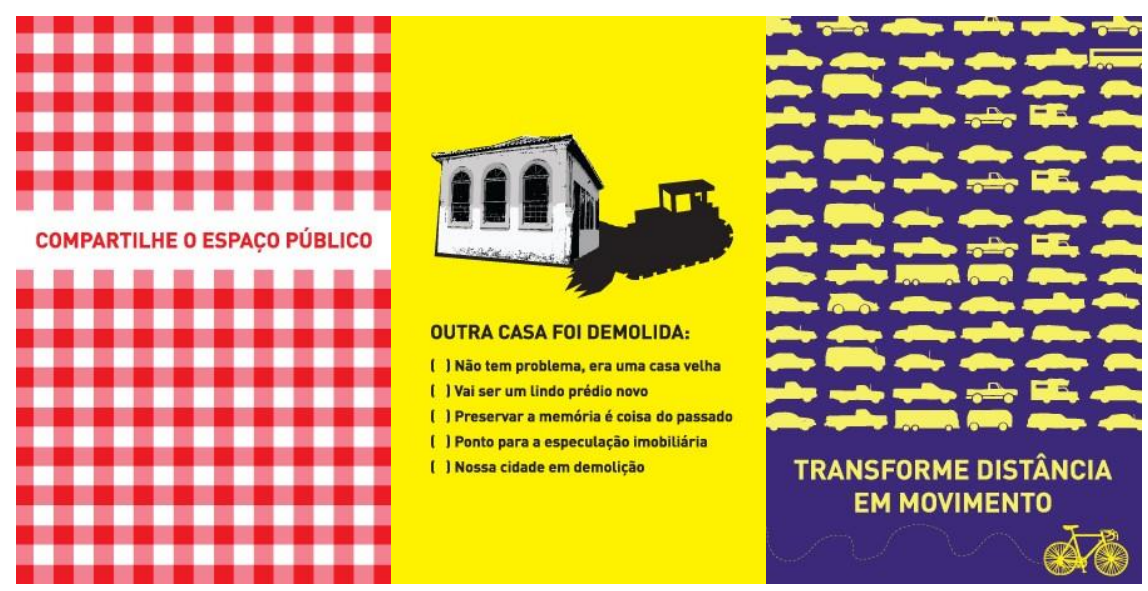

Fonte: Poro, intervenções urbanas e ações efêmeras ${ }^{1}$ (2011)

Para que o projeto fosse implementado com sucesso, a informação demandava clareza para comunicar a mensagem, visto o alcance público almejado para o projeto, além de instigar e sensibilizar, levando o cidadão a refletir sobre o questionamento. O recurso do apelo visual se articula, então, com a mensagem pretendida.

O design não é apenas uma actividade que produz objectos mas é também um processo que permite experienciar ideias. Este processo de entendimento e de comunicação entre o público e o espaço urbano, resulta em experiências significativas para o público que comunica e reage ao ambiente recriado pelo designer. O público é o alvo da experiência, logo deve ser colocado em primeiro lugar, denotando-se uma preocupação com a experiência humana e, com a sua integração no contexto social e cultural do espaço urbano. Para tal, o designer deve proceder a métodos de pesquisa que potenciem o desenvolvimento de comunicações efectivas, entre o objeto de experiência (espaço público) e o utilizador (OLIVEIRA; CASTELA; CARVALHO, 2007, p. 22).

A fim de promover a experiência, o designer deve compreender quais elementos físicos do espaço urbano contribuem para o contato com o indivíduo e induzir comportamentos nos limites estabelecidos.

Uma potencialidade a ser explorada, quando se aborda a experiência no espaço público é a zona híbrida do espaço urbano, ou seja, a calçada. Um elemento de interseção entre a rua e o espaço

\footnotetext{
${ }^{1}$ Disponível em: http://poro.redezero.org/ver/intervencao/por-outras-praticas-e-espacialidades/.
} 
privado, sendo pouco valorizada e que poucas pessoas se apropriam, mas, seu papel é fundamental para a interação entre as pessoas. A zona híbrida, quando utilizada, se torna um lugar no consciente das pessoas e torna as ruas pessoais. O fato de as pessoas se sentirem "em casa" nas suas zonas híbridas resulta em sentimentos de responsabilidade para com o espaço e os entornos. Zonas híbridas são capazes de melhorar o contato social. O entendimento da zona híbrida como um lugar de identificação e apropriação transforma o sentido de uso de espaços antes negligenciados (KARSSENBERG, et al., 2015). Esse "pertencimento" tem impacto no ambiente social imediato através da possibilidade de identificação social. A zona híbrida, quando apropriada, permite que as pessoas se avaliem, se relacionem e se identifiquem umas com as outras (Figura 4).

Figura 4 - Zona híbrida do espaço urbano

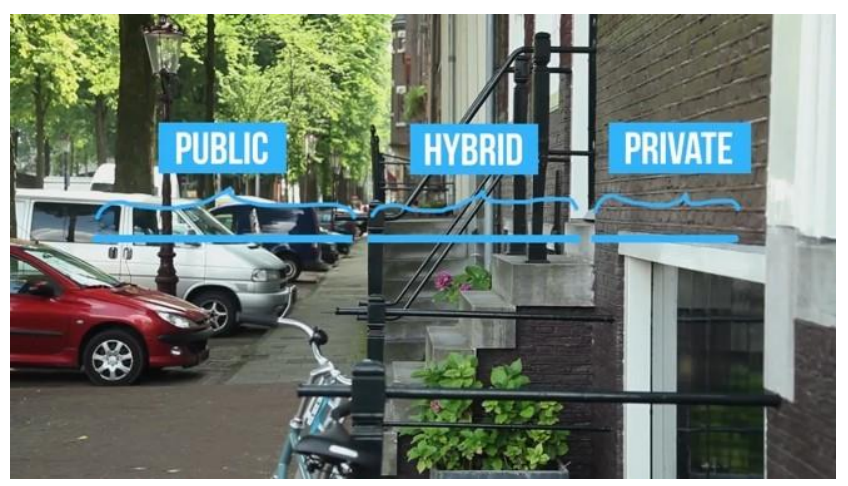

Fonte: CondomínioSC (2016) ${ }^{2}$

Trazer as pessoas para a zona híbrida, para que elas se apropriem do espaço, e não o utilizem somente para circulação, pode ser valorável para a ação dos coletivos urbanos e designers. O espaço fornece o cenário para criar soluções que melhorem o contato das pessoas com a zona pública e produzir a experiência de uma cidade ao nível dos olhos. Na zona híbrida pode-se explorar a interação entre as pessoas e o sentimento de pertencimento. As pessoas buscam conexões que lhes transmitam segurança e se afastam de lugares vazios e sem interação. O uso da zona híbrida demarca os limites entre o público e o privado através do uso. O potencial desse espaço está na capacidade dos coletivos urbanos e designers implementarem atividades múltiplas e diversas, com o apoio do poder público e da população, na busca por referências culturais e individuais que associem as pessoas aos seus meios de convivência, diante das diferentes situações abordadas, e na preocupação com o envolvimento social cotidiano.

\subsection{Visão sistêmica: Movimento Nossa BH}

O Movimento Nossa BH, criado em 2008, é um coletivo voltado para o engajamento social e comprometimento com o exercício da cidadania no espaço público. Para tanto, busca monitorar a agenda das políticas públicas para a efetivação das ações na cidade. Mantém o compartilhamento de experiências com outros coletivos urbanos e com a sociedade através de diálogos, oficinas e seminários. Cada demanda da cidade identificada pela equipe, sempre baseada em indicadores e análises de dados, é exposta em redes sociais para que a informação alcance a população. Para tanto, ele trabalha em rede com a população, outros coletivos, empresas, universidades e o poder

2 Disponível em: http://www.condominiosc.com.br/secoes/cidades/2614-interacao-da-rua-com-edificios-efundamental-para-cidades-mais-seguras. 
público.

A mobilidade urbana é uma questão bastante abordada pelo coletivo e seu diagnóstico envolve a visão sistêmica da problemática na cidade. Num levantamento de dados foi apresentada a participação e os interesses de cada envolvido na mobilidade urbana da cidade, além de questionamentos que incitam a reflexão do contexto atual (Figura 5).

Figura 5 - Quadro de atores na mobilidade urbana e suas formas de atuação na cidade

\begin{tabular}{|c|c|}
\hline ATORES & INTERESSES (diretos e indiretos) \\
\hline Poder público (federal, estadual e municipal) & $\begin{array}{l}\text { Coordenacão, gestão e planejamento } \\
\text { da mobilidade urbana. }\end{array}$ \\
\hline $\begin{array}{l}\text { Operadores do transporte (empresários de ônibus, } \\
\text { empresas de frete e de aplicativos de transporte } \\
\text { (Uber. Cabify, etc.) }\end{array}$ & $\begin{array}{l}\text { Um serviço de qualidade e } \\
\text { manter seus negócios gerando lucro. }\end{array}$ \\
\hline $\begin{array}{l}\text { Trabalhadores (motoristas e agentes de bordo } \\
\text { de ónibus, trabalhadores do metrô, taxistas, } \\
\text { motoristas profissionais, motoboys, caminhoneiros }\end{array}$ & $\begin{array}{l}\text { Boas condiçōes de trabalho } \\
\text { e remuneração. }\end{array}$ \\
\hline $\begin{array}{l}\text { Usuários de transporte (passageiros, ciclistas, } \\
\text { motoristas, pedestres, motociclistas). }\end{array}$ & Segurança e fluidez nos deslocamentos. \\
\hline $\begin{array}{l}\text { Atores urbanos (comerciantes, instituições de } \\
\text { ensino, hospitais, empregadores, etc.) }\end{array}$ & $\begin{array}{l}\text { Rapidez e diminuição de custos gerados } \\
\text { pela dificuldade nos deslocamentos. }\end{array}$ \\
\hline Universidades e órgãos de pesquisa & $\begin{array}{l}\text { Estudos e pesquisas sobre aspectos } \\
\text { e processos ligados à mobilidade urbana. }\end{array}$ \\
\hline $\begin{array}{l}\text { Movimentos Sociais ligados à questão } \\
\text { da mobilidade urbana }\end{array}$ & $\begin{array}{l}\text { Interesses variados no sentido } \\
\text { da mudança social. }\end{array}$ \\
\hline
\end{tabular}

Fonte: http://nossabh.org.br/ficha-1/ (2018)

Um dos objetos de análise do coletivo é o Observatório de Mobilidade Urbana de Belo Horizonte (OBSMOB-BH). Ele foi pensado para intermediar os interesses das instituições quanto à mobilidade urbana na cidade e monitorar o planejamento, implementação e os resultados das metas públicas. Seis indicadores são utilizados pelo Observatório para acompanhar o alcance dos objetivos: pedestres, bicicletas, transporte coletivo, veículos individuais diversos, trânsito e segurança e a preocupação ambiental. Com esses indicadores determina-se as prioridades de atuação das políticas públicas, de acordo com as necessidades de cada grupo e seu respectivo impacto para os demais grupos (Figura 6).

Figura 6 - Plano de mobilidade urbana

Prioridades das politicas

de mobilidade urbana

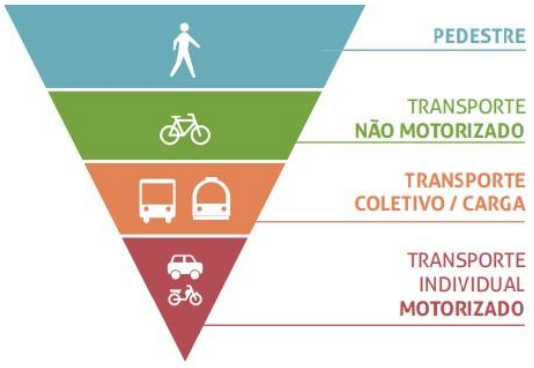

Fonte: nossabh.org.br/ficha-1/ (2018) 
É importante ressaltar que este não é um coletivo que aborda o design de forma direta em suas práticas urbanas, mas que retrata o estudo da mobilidade urbana a partir de uma fundamentação teórica bastante criteriosa. Essa é uma etapa fundamental e deve ser transferida para o contexto de atuação do designer, de forma que ao trabalhar em conjunto com outras áreas, ele tenha a capacidade de elaborar estratégias a partir de um amplo diagnóstico do cenário que lhe é apresentado.

Portanto, analisar ações de coletivos urbanos que não exploram diretamente a atividade do design permite compreender como tais ações são desenvolvidas e implementadas e como elas contribuem para a evolução e desenvolvimento do design, neste cenário de espaço urbano e sociedade.

\section{Desafios para o Design no contexto urbano}

Braida e Nojima (2014) retratam o design como um fenômeno de linguagem e um campo do conhecimento expressado pela prática sociocultural e comunicativa, no qual os produtos de design são sistemas de signos que produzem mensagens, geram significados e discursos, dessa forma, sendo capazes de ressignificar os espaços da cidade. O produto do design, portanto, carrega linguagens e significações, interpretadas como códigos mediadores para as relações dos indivíduos com o mundo real, incentivando novos comportamentos e estilos de vida para os cidadãos. Como afirma Cardoso (2012, p. 117), "por meio da visualidade, o design é capaz de sugerir atitudes, estimular comportamentos e equacionar problemas complexos."

É perceptível o empoderamento e a participação da população na cidade, ainda que exista um individualismo e resistência para contornar a rotina, definir o protagonismo, ampliar a usabilidade e repensar o consumo na cidade exige diálogo e conhecimento por parte da população. $\mathrm{O}$ acesso e a troca de informação são fundamentais nesse processo, no entanto, é necessário que o designer atue de forma colaborativa com agentes locais e cidadãos e em rede (CARDOSO, 2012). Ele deve desenvolver competências com foco na interação, empatia, gestão da informação, desenvolvimento coletivo e análise sistêmica (KRUCKEN, 2008).

\footnotetext{
O modo de atuação no design contemporâneo se faz principalmente por meio da noção e do sistema de coletivos. Ou seja, grupos de criação e desenvolvimento de projetos e produtos onde são relacionados diferentes saberes, provenientes de diferentes áreas de formação e atuação de seus integrantes. Essas novas formas de organização de grupos sem hierarquias reafirmam o esfacelamento do conceito de autoria e confirmam a ação interdisciplinar e as possibilidades transdisciplinares presentes na ação projetual e política (MOURA, 2011, p. 7).
}

A respeito do papel do design na contemporaneidade, há de ressaltar a necessidade de um diagnóstico sobre o atual momento vivido pela sociedade. O design contemporâneo demonstra que as questões da diversidade, multiplicidade, confronto e visões de mundo diferenciadas, interações entre imaginários e culturas, novas construções materiais e simbólicas, multidimensionalidades, fragmentações, metamorfoses, hibridismo e consciência ambiental permeiam os discursos desenvolvidos e construídos no cotidiano. Dessa forma, é natural que o design perca a rigidez de sua atuação, dissolva as práticas e os métodos projetuais antigos e clássicos com o objetivo de estabelecer "a diluição dos segmentos da área do design no sentido de um pensar o design como um todo, um campo maior e mais abrangente, incorporando atitudes e desafios políticos e sociais em busca de um pensamento projetual mais amplo e consistente" (MOURA, 2011, p. 8). 
Assim como aborda Ferreira (2017), demarcar os limites do design ainda é uma atividade difícil, por sua característica complexa e dinâmica. Métodos e processos surgem com o avanço da teoria e da prática, incorporando competências ao design, sem ordenar o conhecimento. Então, o design se fundamenta pela atividade transversal, que se conecta com outras áreas do saber, permitindo, também, a abertura para a contribuição dos usuários na elaboração dos projetos. $\mathrm{E}$ para a criação e implementação de projetos de intervenção urbana no espaço público, essas características são valoráveis ao processo.

O contexto atual se apresenta como um cenário dinâmico. Percebe-se que muitas realidades distintas passam a coexistir de forma conjunta, no qual cada indivíduo, em posse de suas vivências pessoais e sentimentos "tende a conectar-se com a multiplicidade dos valores e dos significados da cultura a qual pertence, isto é, de seu meio social" (CELASCHI; MORAES, 2013, p. 40). Assim, o indivíduo, enquanto cidadão, expressa para o seu meio social aquilo que ele constrói e atribui significado, aquilo que ele molda como parte de sua identidade.

Manzini e Vezzoli (2011) discursam sobre os desafios para o design na sociedade contemporânea e abordam a necessidade dos projetos (produtos e serviços) contribuírem para a qualidade de vida, em que o bem-estar social deixe de ser vinculado ao aumento da disponibilidade de produtos e passem a relacionar-se à convivência. Os autores acreditam que a percepção de bemestar relacionada à convivência permite o desenvolvimento do sentimento de pertencimento, cuja sociedade não se constitui pela soma de indivíduos isolados, mas, por suas conexões.

Portanto, é necessário que o designer inclua no projeto de intervenção urbana os valores culturais do lugar onde ela será implementada, para que os indivíduos possam se identificar com o projeto e se apropriar dele, evidenciando mensagens que transmitem os valores do lugar e as potencialidades percebidas.

\section{Considerações finais}

A intensa ação dos coletivos urbanos no espaço público, cada vez mais frequente, ampliou a participação cidadã na cidade. Nota-se que o comportamento social está relacionado com a configuração e a atividade desempenhada pelo lugar. Os coletivos urbanos buscam, portanto, o resgate da cidadania através da mobilização pública e de intervenções críticas e estratégicas, a fim de melhorar a experiência de viver a cidade. Numa esfera tática, essas ações colocam o cidadão em foco e a cidade se torna uma plataforma para a discussão dos problemas cotidianos e as possíveis formas de ressignificar o espaço urbano de acordo com o interesse público.

Em Belo Horizonte, os coletivos urbanos parecem dialogar em suas temáticas. Abordam questões como a valorização da memória e identidade local, a mobilidade, a segurança nas ruas e a sociabilidade. Como apontado, Belo Horizonte já foi considerada a cidade tediosa, na qual costumava-se ouvir da população e turistas que em Belo Horizonte há pouca atratividade e não há muito o que fazer na cidade. Mas, recentemente, a cidade viu emergir o sentimento de resgate da vivência urbana, com a intensificação dos movimentos coletivos. Sua imagem vem sendo reconstruída na medida em que a participação cidadã se torna mais efetiva. $O$ design surge, nesse processo, como mediador, a fim de fomentar a ação dos coletivos urbanos na transformação do espaço público.

A participação cidadã impulsionada pela prática do design, e em conjunto trabalho à uma equipe multidisciplinar, fortalece a inclusão social. Por meio de práticas inovadoras, tecnológicas ou 
não, o cidadão pode construir seu cenário de atuação. Englobar o estudo de diferentes culturas, habilidades distintas e conhecimentos integrados por meio de uma visão sistêmica e focada na solução de problemas complexos que englobem o contexto local é uma vertente do design. 0 exercício da democracia em uma sociedade, não deve, portanto, se basear em um contexto global, uma vez que cada cultura possui suas particularidades.

No entanto, a atitude dos designers deve ser fundamentada, uma vez que, qualquer transformação urbana deve considerar a identidade do lugar, não conferindo a ele um sentido de embelezamento visual, mas de significado. A complexa dinâmica do espaço urbano determina que designers busquem trabalhar de forma colaborativa e multidisciplinar.

Cabe aqui ressaltar que, mesmo com a relevância do papel do design para a problemática urbana atual, percebe-se pouco aprofundamento teórico e capacitação dos profissionais que abordam a temática design e democracia. É um campo novo de atuação do designer, sobretudo no Brasil, e, portanto, seu estudo necessita ser ampliado, considerando a tendência da pesquisa sobre o futuro e a transformação das cidades aumentar consideravelmente.

\section{Agradecimentos}

Esta pesquisa tem o apoio da CAPES (Coordenação de Aperfeiçoamento de Pessoal de Nível Superior) com a concessão de bolsa de estudo.

\section{Referências}

BATISTA, Elisangela. Direito à cidade: o Design no processo de retomada da cidade de Belo Horizonte. Cuadernos del Centro de Estudios de Diseño y Comunicación, v. 69, p. 137-150, 2017. Disponível em: <http://www.scielo.org.ar/scielo.php?script=sci_arttext\&pid=S185335232018000400012>. Acesso em: 08 mar. 2018.

BAUMAN, Zygmunt. Confiança e medo na cidade. Tradução de Eliana Aguiar. Rio de Janeiro: Zahar, 2009. Disponível em: <https://vk.com/doc259715455_314861544?hash=126b15f7cc4c4e0034\&dl=8c8309620341bc 2ba0>. Acesso em: 08 mar. 2018.

BENTZ, I. M. G. A arte no espaço urbano: narrativas visuais. Strategic Design Research Journal, v. 7 (1), $\quad$ p. $\quad$ 07-14, $2014 . \quad$ Disponível em: http://www.revistas.unisinos.br/index.php/sdrj/article/download/sdrj.2014.71.02/4325>. Acesso em: 06 mar. 2018.

BOTELHO, T. R. A revitalização da região central de Fortaleza (CE): novos usos dos espaços públicos da cidade. In: FRÚGOLI Jr., Heitor; ANDRADE, Luciana Teixeira de; PEIXOTO, Fernanda Arêas. (Orgs.). As cidades e seus agentes: práticas e representações. São Paulo; Belo Horizonte: EDUSP; PUCMinas, 2006, p. 45-67.

BRAIDA, F; NOJIMA, V. L. M. S. Por que design é linguagem? Rio de Janeiro: Rio Book's, 2014.

CANEVACCI, Massimo. A cidade polifônica: ensaio sobre a antropologia da comunicação urbana. 2. ed. São Paulo: Studio Nobel, 2004. Disponível em: <https://books.google.com.br/books?isbn=8585445084>. Acesso em: 27 fev. 2018.

CARDOSO, Rafael. Introdução à história do design. São Paulo: Editora Blucher, 2008.

. Design para um mundo complexo. São Paulo: Cosac Naify, 2012. 
CELASCHI, F.; MORAES, D. Futuro, bem-estar, interdependência: palavras-chave para o design contemporâneo. In: CELASCHI, F.; MORAES, D. (Orgs). Cadernos de Estudos Avançados em Design: Design e Humanismo. Barbacena: EdUEMG, 2013. v. 7, p. 35-60.

FERREIRA, Isabela de Mattos. Design transversal e as práticas de ressignificação para a cidadania no espaço público. 2017. 188 f. Tese (Doutorado em Design) - Pontifícia Universidade Católica do Rio de Janeiro, Departamento de Artes e Design Rio de Janeiro, Rio de Janeiro. 2017.

JAYME, Juliana Gonzaga; TREVISAN, Eveline. Intervenções urbanas, usos e ocupações de espaços na região central de Belo Horizonte. Civitas - Revista de Ciências Sociais, [S.I.], v. 12, n. 2, p. 359-377, 2012.

Disponível

em:

<http://revistaseletronicas.pucrs.br/ojs/index.php/civitas/article/view/11933/8133>. Acesso em: 27 fev. 2018.

KARSSENBERG, Hans. et al. A cidade ao nível dos olhos: lições para os plinths. Porto Alegre: EDIPUCRS, 2015. Disponível: <http://livrariaedipucrs.pucrs.br/>. Acesso em: 05 mar. 2018.

KRUCKEN, Lia. Competências para o design na sociedade contemporânea. In: MORAES, Dijon de; Krucken, Lia. (Org.). Cadernos de estudos avançados em design: transversalidade. Ed UEMG, 2008. caderno 2, v. 1. p. 23-32.

MACHADO, Jorge Alberto S. Ativismo em rede e conexões identitárias: novas perspectivas para os movimentos sociais. Sociologias, n. 18, p. 248-285, 2007. ISSN 1517-4522. Disponível em: <http://dx.doi.org/10.1590/S1517-45222007000200012>. Acesso em: 26 fev. 2018.

MANZINI, E.; VEZZOLI, C. O desenvolvimento de produtos sustentáveis: os requisitos ambientais dos produtos industriais. São Paulo: Edusp, 2011.

MICRÓPOLIS. Coletivo urbano que realiza intervenções com foco na transformação do espaço urbano e na vivência da cidade. Disponível em: <http://www.micropolis.com.br/>. Acesso em: 08 mar. 2018.

MOREIRA, Corina Maria Rodrigues. Patrimônio cultural e revitalização urbana. Usos, apropriações e representações da Rua dos Caetés. 2008. Dissertação (Mestrado em Ciências Sociais) - Pontifícia Universidade Católica de Minas Gerais, Belo Horizonte, 2008.

MOURA, M. Interdisciplinaridades no Design Contemporâneo. In: Menezes, Marizilda; Paschoarelli, Luis Carlos; Moura, Mônica. (Org.). Metodologias em Design: Inter-Relações. 1ed. São Paulo: Estação das Letras e Cores, 2011, v. 1, p. 274-290.

OLIVEIRA, Eunice de; CASTELA, Sara de; CARVALHO; Susana. Experiência no espaço público. Lisboa: DCiii, 2007. Disponível em: <http://areas.fba.ul.pt/in2places/images/objecto_sustentacao.pdf>. Acesso em: 05 mar. 2018. 